\title{
Cécile Le Cornec-Rochelois, Anne Rochebouet, Anne Salamon (dir.), Le texte médiéval. De la variante à la recréation
}

\section{Walter Meliga}

\section{(2) OpenEdition}

\section{Journals}

\section{Edizione digitale}

URL: http://journals.openedition.org/studifrancesi/1219

DOI: 10.4000/studifrancesi. 1219

ISSN: 2421-5856

\section{Editore}

Rosenberg \& Sellier

\section{Edizione cartacea}

Data di pubblicazione: 1 décembre 2015

Paginazione: 558

ISSN: 0039-2944

\section{Notizia bibliografica digitale}

Walter Meliga, «Cécile Le Cornec-Rochelois, Anne Rochebouet, Anne Salamon (dir.), Le texte médiéval. De la variante à la recréation », Studi Francesi [Online], 177 (LIX | III) | 2015, online dal 01 décembre 2015, consultato il 10 janvier 2021. URL: http://journals.openedition.org/studifrancesi/1219; DOI: https:// doi.org/10.4000/studifrancesi. 1219

Questo documento è stato generato automaticamente il 10 janvier 2021.

\section{cc) (†)}

Studi Francesi è distribuita con Licenza Creative Commons Attribuzione - Non commerciale - Non opere derivate 4.0 Internazionale. 


\title{
Cécile Le Cornec-Rochelois, Anne Rochebouet, Anne Salamon (dir.), Le texte médiéval. De la variante à la recréation
}

\author{
Walter Meliga
}

\section{NOTIZIA}

CÉCILE LE CORNEC-ROCHELOIS, ANNE ROCHEBOUET, ANNE SALAMON (dir.), Le texte médiéval. De la variante à la recréation, Paris, Presses de l'Université Paris-Sorbonne, 2012 («Cultures et civilisations médiévales», 54), pp. 274.

1 Il volume discende da un incontro di studi dell'Università di Paris-Sorbonne e raccoglie diversi interventi sulla questione, particolarmente sentita nella cultura accademica francese, della variazione ovvero della mobilità del testo medievale. Le ricerche si richiamano alle celebri nozioni di mouvance di Paul Zumthor (1972) e di variance di Bernard Cerquiglini (1989), anche se con una buona capacità di analisi e di approfondimento autonomi e con una sensibile indipendenza rispetto a quelle formulazioni teoriche, più brillantemente esposte che sostenute da un'effettiva pratica filologica ed editoriale. La varietà delle prospettive di analisi - filologica, letteraria, linguistica, codicologica, iconografica-consente di affrontare diverse situazioni testuali, anche se il ventaglio della letteratura presa in esame, per quanto ampio, resta sostanzialmente limitato al romanzo e al racconto cortesi d'oil (la considerazione dell'epica e della lirica avrebbe certamente offerto campi di riflessione ancora più ampi).

2 Dopo un'introduzione di Joëlle Ducos (Avant-propos: Variance, variante, variation) e un intervento metodologico di Patrick MORAN, Le texte médiéval existe-t-il? Mouvance et identité textuelle dans les fictions $d u x_{\text {XIII }}^{e}$ siècle, la prima parte («Le philologue et les 
variantes») comprende gli interventi di: Stefania MAFFEI, Mouvance de l'œuvre, fixation du texte: essai d'édition critique de quelques passages de "Guillaume d'Angleterre"; Oreste FLOQUET e Sara CENTILI, Pour une grammaire de la mouvance: analyse linguistique de quelques structures adiaphores; Gilles Roussineau, De l'utilité des variantes pour l'édition de textes; Matthieu MARCHAL, Variations lexicales et édition: étude comparée des deux témoins manuscrits de "Gérard de Nevers", mise en prose du "Roman de la Violette"; Thomas VERJANS, Le linguiste et la variante: quelle(s) leçon(s) en tirer?; Marc KIWITT, Le problème de la variance et l'édition des textes en ancien français rédigés en caractères hébreux; Christine SILVI, La mouvance du livre imprimé en français: l'exemple des incunables du "De proprietatibus rerum" de Barthélemy l'Anglais dans la traduction de Jean Corbechon. La seconda parte ("L'auteur, le copiste, l'enlumineur: variance et création») è composta da: Nathalie KOBLE, L'intratextualité inventive: la singularité critique d'un compilateur de lais; Olivier DELSAUX, Variantes d'auteur ou variance de copiste: 'l'escripvain' en moyen français face à la mouvance de ses manuscrits; Stefania CERRITO, Entre Ovide et "Ovide moralisé": la variance des traductions des "Métamorphoses" au Moyen Âge et à la Renaissance; Florence TANNIOU, Les variantes et le sens de la réécriture dans les versions du "Landomata"; Sandrine HÉRICHÉ-PRADEAU, "Ceste lame n'ert ja levee» ou l'esthétique du retable dans le "Lancelot propre"; Irène FABRY, L'ambassade $d u$ roi Loth et de ses fils auprès des barons rebelles: variations iconographiques; Matthieu VERRIER, Variations sur le mythe d'Actéon dans les enluminures de l'"Ovide moralisé" et de l"'Epistre Othea". Una breve Conclusion di Françoise VIELLIARD chiude il volume. 